\title{
The contemporary cultural significance of Gallery Rock, a petroglyph complex recently found in Wollemi National Park, New South Wales, Australia
}

\author{
Paul S.C. Taçon, ${ }^{1}$ Wayne Brennan, ${ }^{2}$ Graham King, ${ }^{2}$ \\ Dave Pross ${ }^{3}$ and Matthew Kelleher ${ }^{4}$ \\ 1. Place Evolution and Rock Art Heritgae Unit, School of Humanities, Gold Coast campus, Griffith University, QLD 4222. \\ Email: p.tacon@griffith.edu.au; Phone: 0755529074
}

2. Blue Mountains Aboriginal Community and Burramoko Archaeological Services, PO Box 217, Katoomba, NSW 2780

3. Darkinjung and Guringai Local Community, PO Box 7161, Kariong, NSW 2250

4. Kelleher Nightingale Consulting, Suite 911-912, 155 King St., Sydney, NSW 2000

\begin{abstract}
In 2001 we began The Landscape of Blue Mountain Rock Art research project. Since then, over 250 rock art sites have been recorded in Wollemi National Park, consisting of engravings, drawings, stencils and some paintings. Two of the largest, best preserved and culturally significant sites are Eagle's Reach, with drawings and stencils, and Gallery Rock, an engraved platform. Although images were made using very different techniques there are many common subjects and stylistic features between the sites. Each location also shares imagery with smaller sites across southern Wollemi, where most research has been undertaken. For contemporary Aboriginal people of the Greater Blue Mountains World Heritage Area these two sites are highly significant as inter-related cultural places that are focal points within larger cultural landscapes. In this paper, we report the contemporary cultural significance of Gallery Rock and articulate its relationship to Eagle's Reach and other nearby rock shelter art sites. Discussion focuses on the interpretation of some figures as key Ancestral Beings and whether some, such as Baiame, have a preEuropean settlement context, something of great interest to John Clegg who visited Gallery Rock in 2007.
\end{abstract}

Keywords: Wollemi, rock art, engravings, Gallery Rock, Eagle's Reach, Culture Heroes, Baiame, Daramulan

\section{Introduction}

Before 2001, Wollemi National Park (New South Wales, Australia) had not been surveyed for cultural heritage sites, partly because many people believed it was too rugged and wild, and that no sites would be found. But there are thousands of known sites around the edges (e.g. see Dibden 2011; Kelleher 2002; McDonald 2008a; Officer 1992; Sim 1966, 1969) and Aboriginal community members we consulted suggested there were many within Wollemi yet to be found and documented. This prediction was correct as our team, consisting of Aboriginal community members, archaeologists, NPWS staff, students and bushwalkers, has since documented over 200 previously unrecorded sites, most with rock art, in wild, rugged locations. Some of these sites, such as Gallery Rock (Figure 40) and Eagle's Reach (see Taçon et al. 2008), have spectacular engraved, drawn, painted and stenciled rock art of significance to the contemporary Greater Blue Mountains Aboriginal community.

This research is part of a highly collaborative project designed to better understand the relationship between the cultural heritage, especially rock art sites, of the Greater Blue Mountains World Heritage Area and that

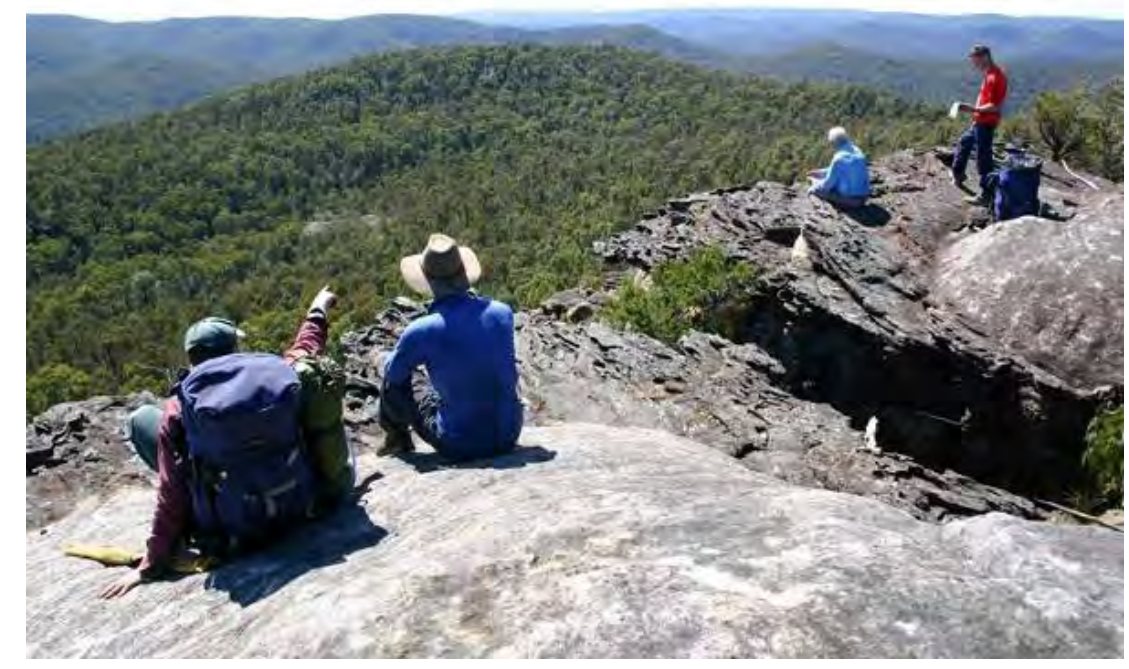

Figure 40. View northwest to Gallery Rock, located in the saddle of two ridgelines, southern Wollemi National Park soon after discovery in September 2006 (photo by Tristram Miller). 
of other parts of New South Wales and to describe culture change in Wollemi National Park over the past few thousand years. Research involved extensive ongoing community consultation and participation. Fieldwork was concentrated in the southern half of Wollemi National Park, within the Greater Blue Mountains World Heritage Area.

Besides documenting sites archaeologically, contemporary Aboriginal views on Wollemi rock art were recorded. Because there has not been continuity in rock art production and use since soon after contact with Europeans, views about what the image represents and/or reasons an image was depicted at a particular location will necessarily be speculative and

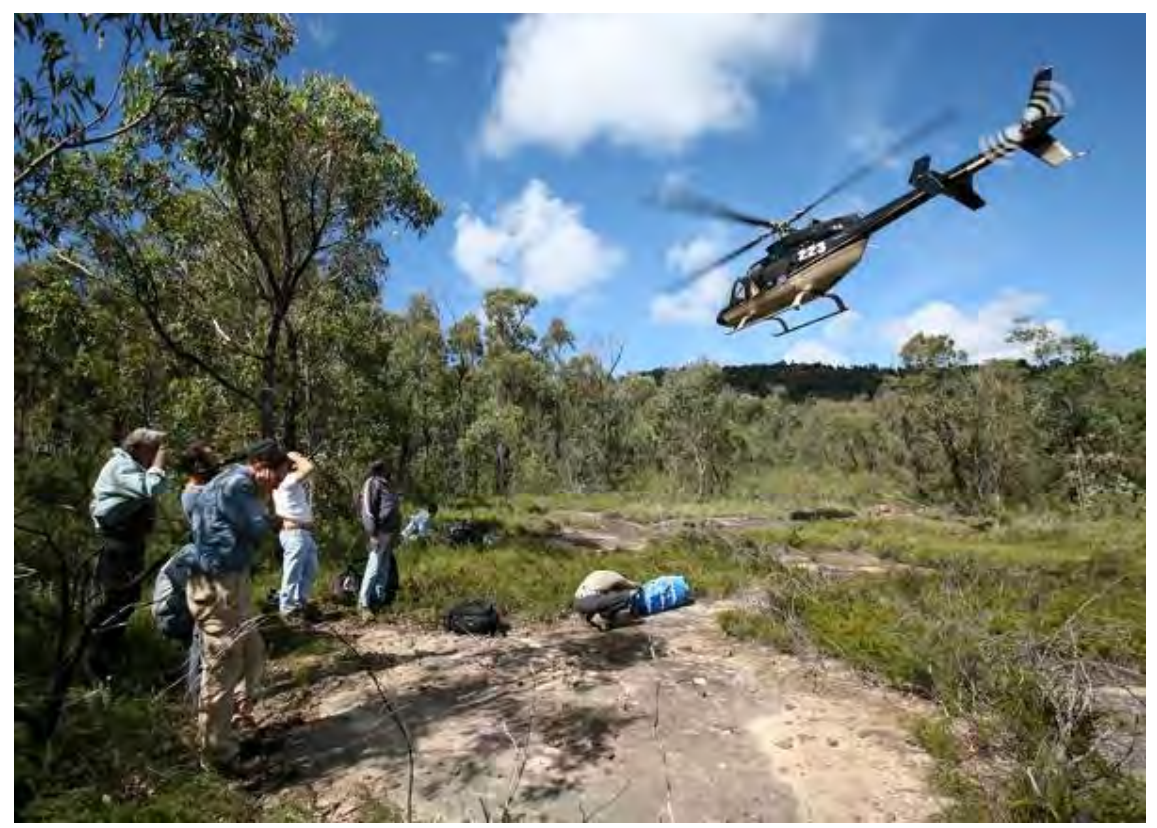

Figure 41. The first recording expedition began with arrival by helicopter in April 2007 (photo by Tristram Miller). The hanging swamp is beyond and above the platform, the creek-fed pool is to the left of the party, the main engraved panels (C and E) are to the right and the cliff edge is below, a few metres beyond where the photograph was taken.

open to debate. Thus, we do not argue that contemporary Indigenous interpretations are necessarily the same as those held by Aboriginal people hundreds of years ago, as all rock art meaning changes over time. Instead, we were interested in the contemporary relevance of rock art for the Aboriginal community - what it means to people today, why it is important to document and protect and so forth. However, contemporary Indigenous significance is often grounded in a cultural perspective different from that of Western scientists. In this regard, contemporary Indigenous meaning can yield hypotheses worth testing by other means (see Taçon et al. 2010; various papers in Brady and Taçon 2016), such as formal methods of rock art analysis (see Taçon and Chippindale 1998). With this in mind, we took a cross-section of the Aboriginal community associated with Wollemi to Gallery Rock as well as various rock art experts, including John Clegg, to record a diversity of contemporary responses to the site and its imagery.

The result is that in this paper the focus is more anthropological than archaeological and it is important to keep this in mind. As Brady and Taçon (2016) note in the conclusion to their book:

rock art has, more often than not, been linked to archaeological discourse where research questions have focused on the past function and symbolism of sites and motifs, quantitative studies involving classifying and analysing the stylistic attributes of motifs, and to science-based investigations such as dating and pigment analysis (among others). Whilst we have no hesitation in acknowledging the importance of such studies in learning more about rock art in archaeological contexts, our contributors have clearly demonstrated the importance of considering the complex contemporary social dimensions of rock art from Indigenous and nonIndigenous perspectives. They have also shown that by engaging with questions concerning what rock art does and how it functions in the present we are better able to understand rock art significance and symbolism in multiple domains including political, legal and educational settings.

\section{The Gallery Rock engraved platform}

Gallery Rock (Figure 40) was found while undertaking survey in September 2006, along with 47 other sites, including another 39 with rock art, but only 3 with engravings. Since then, and as a result of The Landscape of Blue Mountain Rock Art research project, Gallery Rock has become a Wollemi cultural heritage focal point for the contemporary Greater Blue Mountains Aboriginal community. Gallery Rock consists of an engraved Hawkesbury sandstone platform on the edge of a cliff, in an area of spectacular scenery. It is situated in a saddle of a major ridge line, with peaks on either side above. It is bordered by a small hanging swamp so that water runs across the platform (Figure 41) in dry conditions and the top of the site forms a large waterfall during heavy rain. A small creek flows into a large waterhole at the northeast corner of the site, providing drinking water for much of the year. There is a habitable rock shelter behind the waterfall about 25 metres below. 
This combination of geology and general landscape features make the site an unusual location in relation to the rest of Wollemi National Park. In many ways Gallery Rock can be considered a 'liminal' locality, a focal point of local landscape change with unique environmental features. It is ideally suited as a place for rock art not only because of this unusual landscape setting (see Kelleher 2002, 2009 for other examples of such places across the Blue Mountains to the south) but also the fact that there is an expansive flat area of sandstone that is good for making large and numerous petroglyphs, there is water and other resources nearby and that the platform sits in the middle of a ridge-line that could be used for east-west travel across southern Wollemi. In terms of the number of engravings, it has more images than any other known engraving site in the Greater Blue Mountains World Heritage Area and is among the larger petroglyph sites of the greater Sydney region, as revealed by a literature review (e.g. see Campbell 1899; Stanbury and Clegg 1990).

Gallery Rock contains imagery similar in subject matter and style to some of the archaeologically most important sites elsewhere in Wollemi and closer to the coast (see Campbell 1899, McCarthy 1946, 1954, 1959, McDonald 2008a and Sim 1966). It is in a remarkably good state of preservation but petroglyphs are best viewed near dawn and dusk, when the sun is low, or at night with torches shone at oblique angles. Detailed recording took place on four occasions between April - September 2007, with John Clegg briefly participating in one of these trips. During each visit to Gallery Rock a large number of Aboriginal community members participated, both male and female and ranging in age from 17 to 78 . A final trip was undertaken in March/April 2009 so that other community members could visit.

The platform is about the size of half a football field and contains twelve discrete panels with figurative engravings and/or grooves. All have imagery except one panel, located in a creek bed at the northern edge of the platform. It has a cluster of 15 axe (also known as hatchet) grinding grooves. Sixty-eight rock markings were recorded with drawings, photography and precise measurement: 48 figurative motifs (engraved outline forms), sixteen axe grinding grooves and four spear sharpening grooves (Table 5). Most figurative motifs are close to life size. There are male and female humanlike figures, macropods, birds, eels and a rare engraved wombat. Some of the male human-like figures with hands next to engraved animals were interpreted as humans reaching up to or grabbing hold of a bird, a macropod and the wombat. These compositions were also interpreted

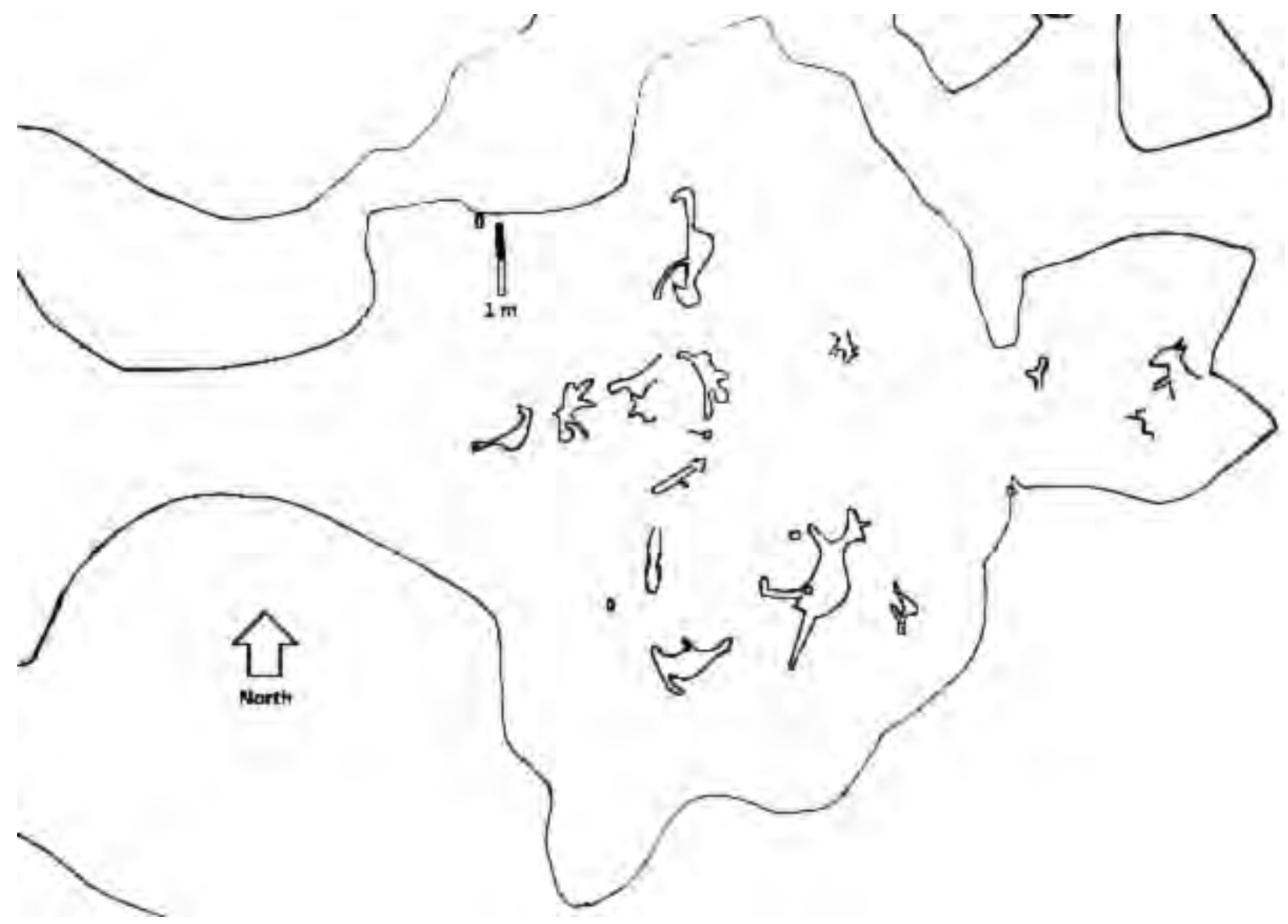

Figure 42. Panel $\mathrm{E}$ with eels in the middle and a large macropod and dingo near the bottom. Hump-back human-like figures are near the top (drawing by Wayne Brennan and Chel Roxburg). 
Table 5. Gallery Rock has 68 rock markings in twelve panels/marked areas; measurements are height by width. Figure numbers are related to location and recording order.

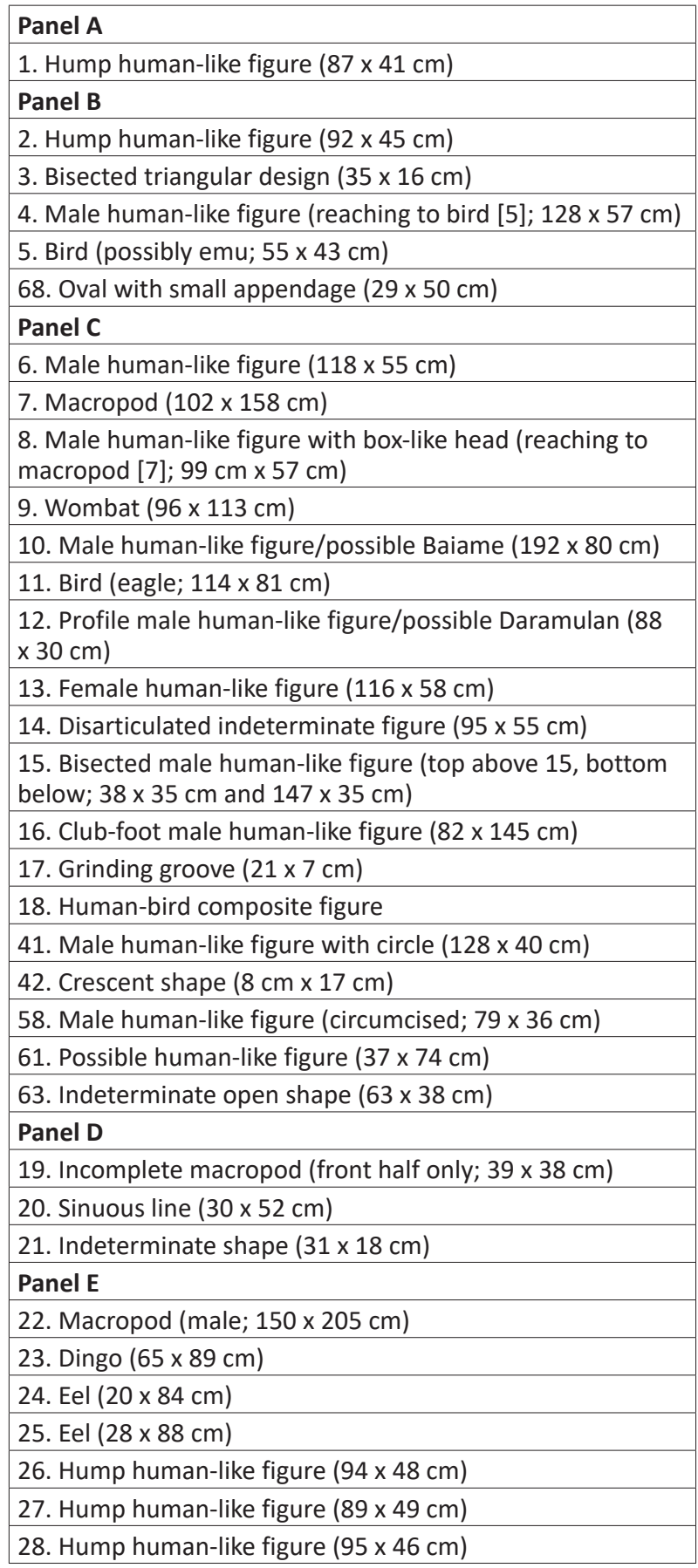

by some Aboriginal community members as males who have just carried prey back to camp on their shoulders and then thrown them on the ground. As with much rock art and contemporary visual Aboriginal art, different forms of meaning can be embedded in or drawn from particular designs and compositions in contemporary (and presumably past) contexts.

Two other compositions show dingoes in relation to other animals. In one, a dingo was placed as if following a large macropod (Figure 42) and a duck. In the other

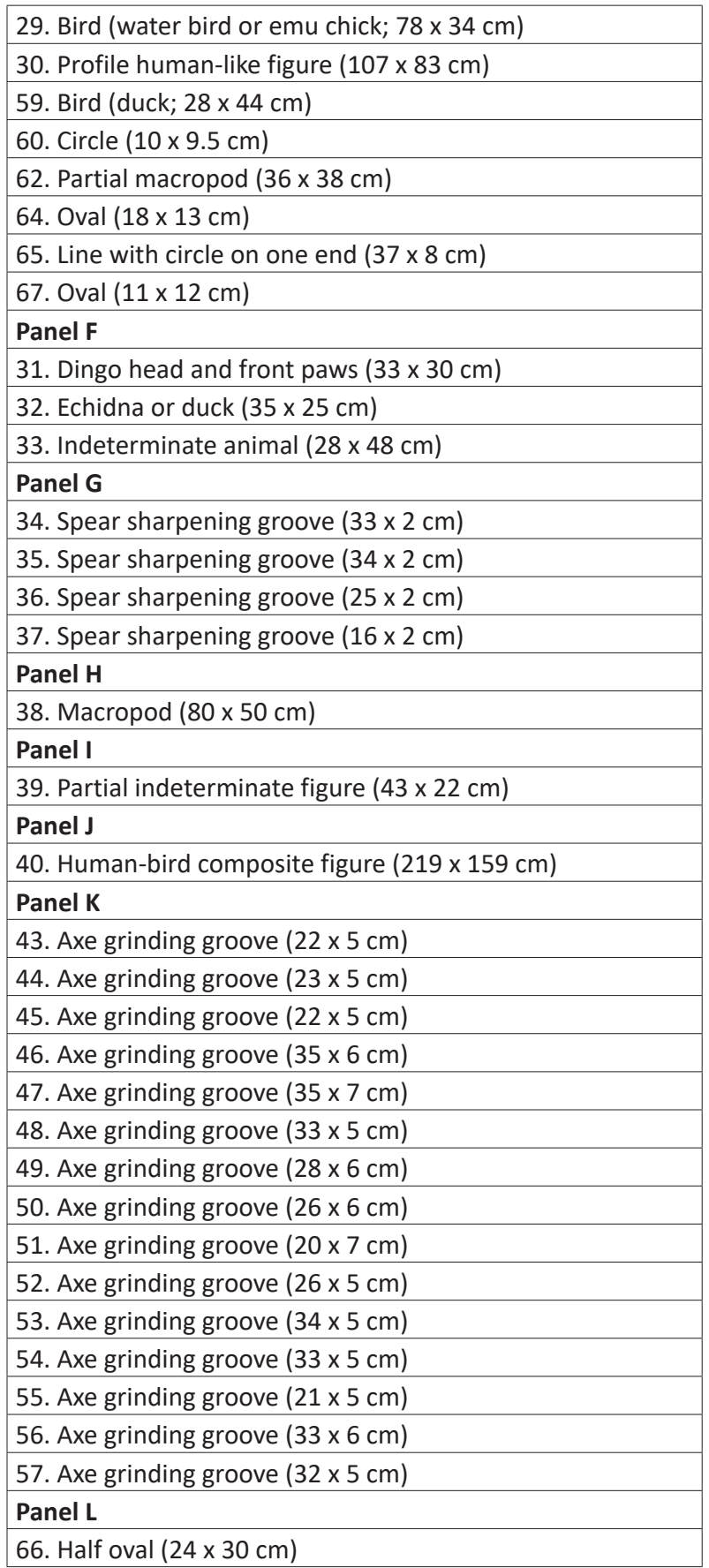

the front half of a dingo was depicted in a pouncing pose near a small animal. There are also motifs that other researchers, such as Higgs and Clegg (2004), McCarthy (e.g. 1959), McDonald (e.g. 2008a) and others, have classified as typical portrayals of 'Culture Heroes'.

\section{Culture Heroes}

In the rock art of the greater Sydney region many engraved or drawn images labelled 'Culture Heroes' have been identified. McCarthy (1959) was the first to 
note them at rock art sites. In a comprehensive study, McDonald (2008a) found there are 29 sites across the Sydney region with 36 engraved depictions of Culture Heroes (2008a:286) and 18 pigment depictions at 9 shelter sites (2008a:336). For engravings she states, 'This motif differs from ordinary anthropomorphs on the basis of extreme size... The two main forms of culture hero are the 'Daramulan' type (partially or fully in profile) and the 'Biaime' type (in plan, with limbs akimbo)' (2008a:286). McDonald notes these figures are restricted to the Guringai, Darug and Darkinjung, that most of the motifs occur singly but occasionally are paired (either two males or a male and female), that Biaime motifs are widespread while Daramulan figures are mostly in the Guringai area, and that the two Daramulan motifs outside this area are in places that could be aggregation localities 'or at least on access routes where group cohesion is being demonstrated' (2008a:286). In early literature (e.g. Mathews 1905; Parker 1905), Biaime, variously spelt and also known by other names such as Bunjil (Howitt 1904), is often referred to as the most powerful Culture
Hero or Creation Being for the people of southeast Australia and is sometimes referred to as 'all-father', the father of all totems and, hence, people. As Parker (1905:7) states, 'Byame... is the original source of all totems, and of the law that people of the same totem may not intermarry'.

In Sydney region rock art large profile anthropomorphs are identified as Daramulan because Mathews (1904) recorded that Dharamulan was:

a sort of half brother or near relative of Baiame's. His name is made up from dhurra, thigh, and mulan, one side, the whole name meaning leg-on-one-side, as he is said to possess one leg only. ... He has a voice like rumbling distant thunder. It fell to his lot to separate the youths from their mothers and teach them the Burbung ceremonies. ... A bullroarer is also frequently called Dharamulan, its humming sound ... represents his voice. ... he has the magical power of changing his shape, and making his body smaller and larger at pleasure ... (Mathews1904:343-5).

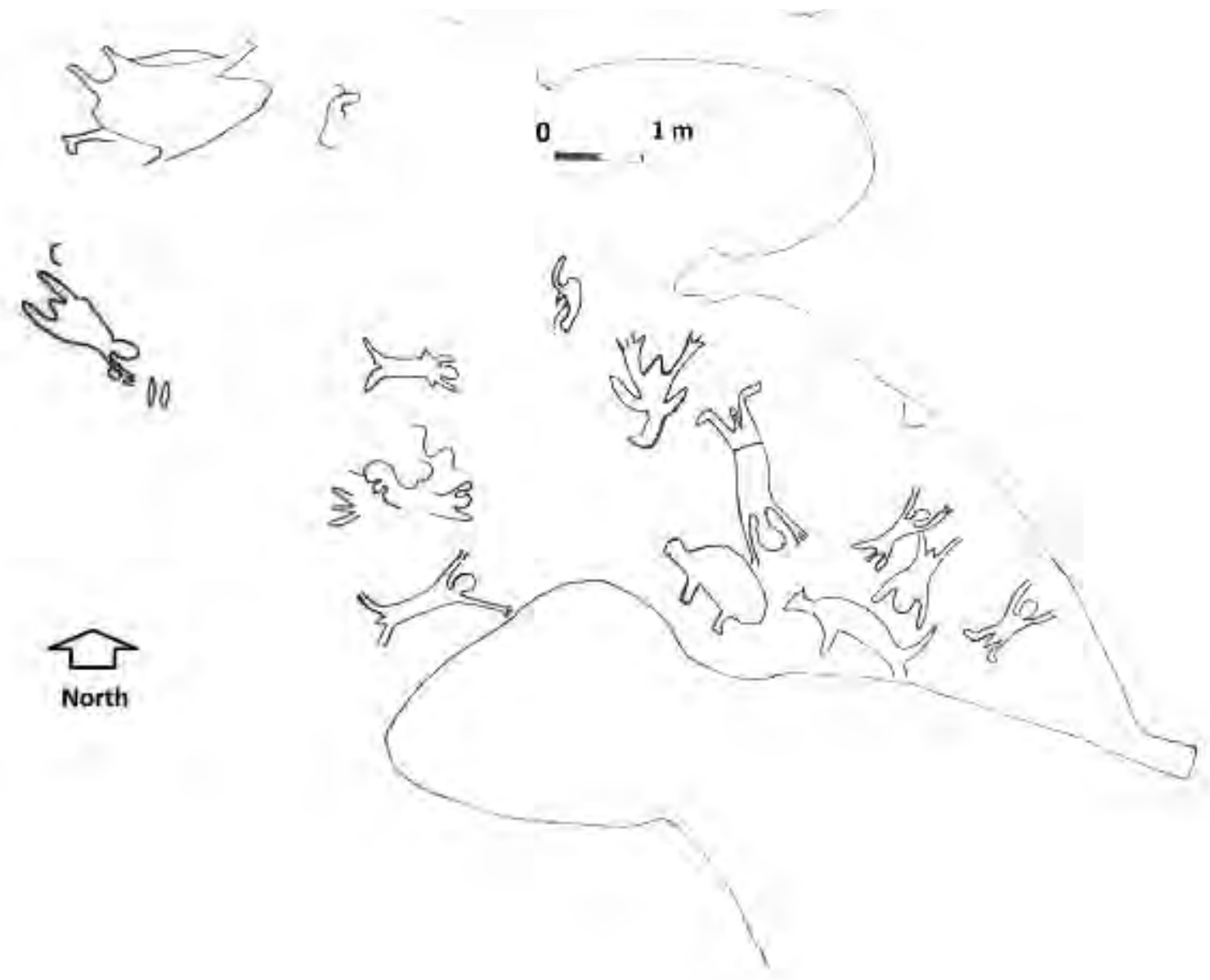

Figure 43. Panel $\mathrm{C}$ with depictions of Ancestral Beings and animals. From top to bottom left (west) side: transforming figure; unknown; 'Biaime' reaching for a circle; female human figure; disarticulated male figure; club-foot male figure. From top to bottom right (east) side: 'Daramulan'; Eagle; ‘Biaime'; human male figure; wombat; human male figure with broad head reaching for macropod; human male figure; macropod (drawing by Wayne Brennan and Chel Roxburg). 


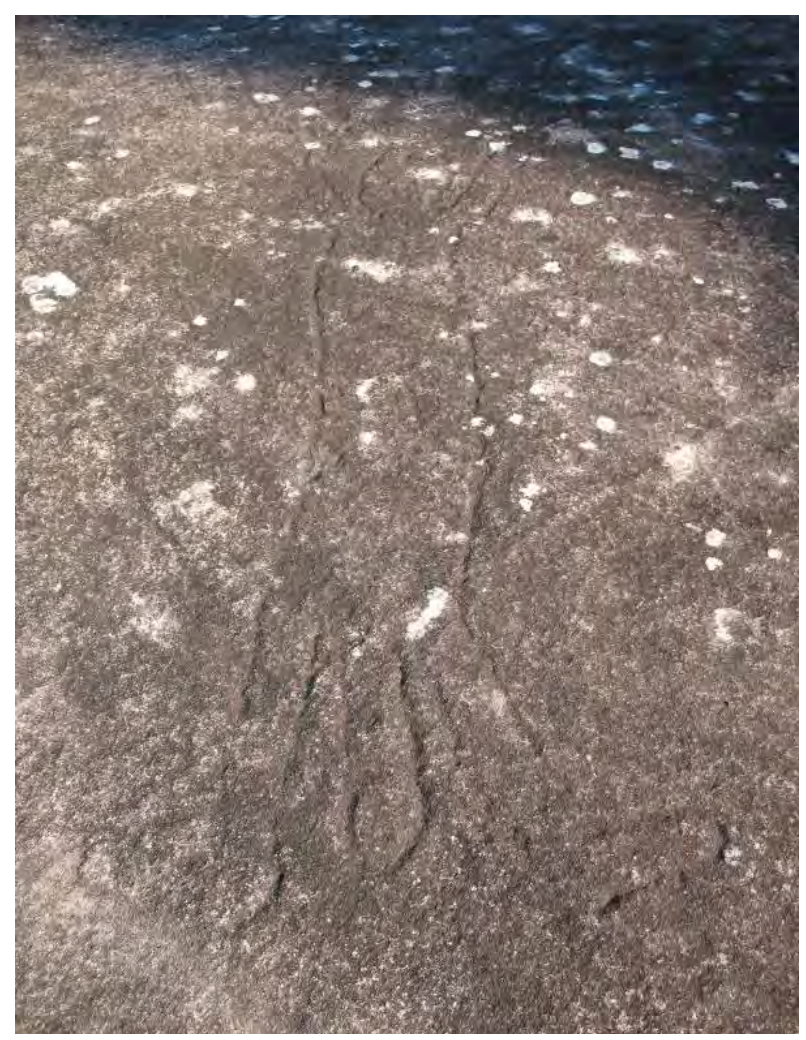

Figure 44. A large human-like figure with Biaime characteristics, such as a long circumcised penis was engraved on the platform amongst other Ancestral Beings (photo by Paul S.C. Taçon).
Clegg and Higgs (2004; see also Higgs 2003) argue that depictions of Daramulan are not only shown in profile but also have an emu (or human) 'bum' and have a human foot (Clegg and Higgs 2004:15), but that 'There is no single or standard graphic Daramulan' (2004:20). Most are large, over a metre high, but a few are small. They also note that many Culture Hero depictions have bird-like heads, as does McDonald (2008a:286-287). Dibden (2011) and others have recorded Daramulan type figures on the greater Woronora Plateau, including dozens of drawings of this Culture Hero, often with prominent bums.

At Gallery Rock, there are numerous depictions of what can be interpreted as the key Culture Heroes of the region, based on the previous research of Dibden, McCarthy, McDonald, Clegg, Higgs, Sim (1969) and others, especially in Panel C (Figure 43), as well as contemporary Aboriginal reactions to the imagery. These include Biaime (Figure 44), Daramulan (in profile and similar to two other engraved figures at nearby sites), an eagle interpreted by Aboriginal community members as the Eagle Ancestor (also called Eaglehawk) that led one of the two moieties of the region (Figure 45), a female human-like figure interpreted as Daramulan's wife by contemporary Aboriginal visitors, hump-back human figures interpreted by contemporary Aboriginal community members as emu-women (Figure 46),

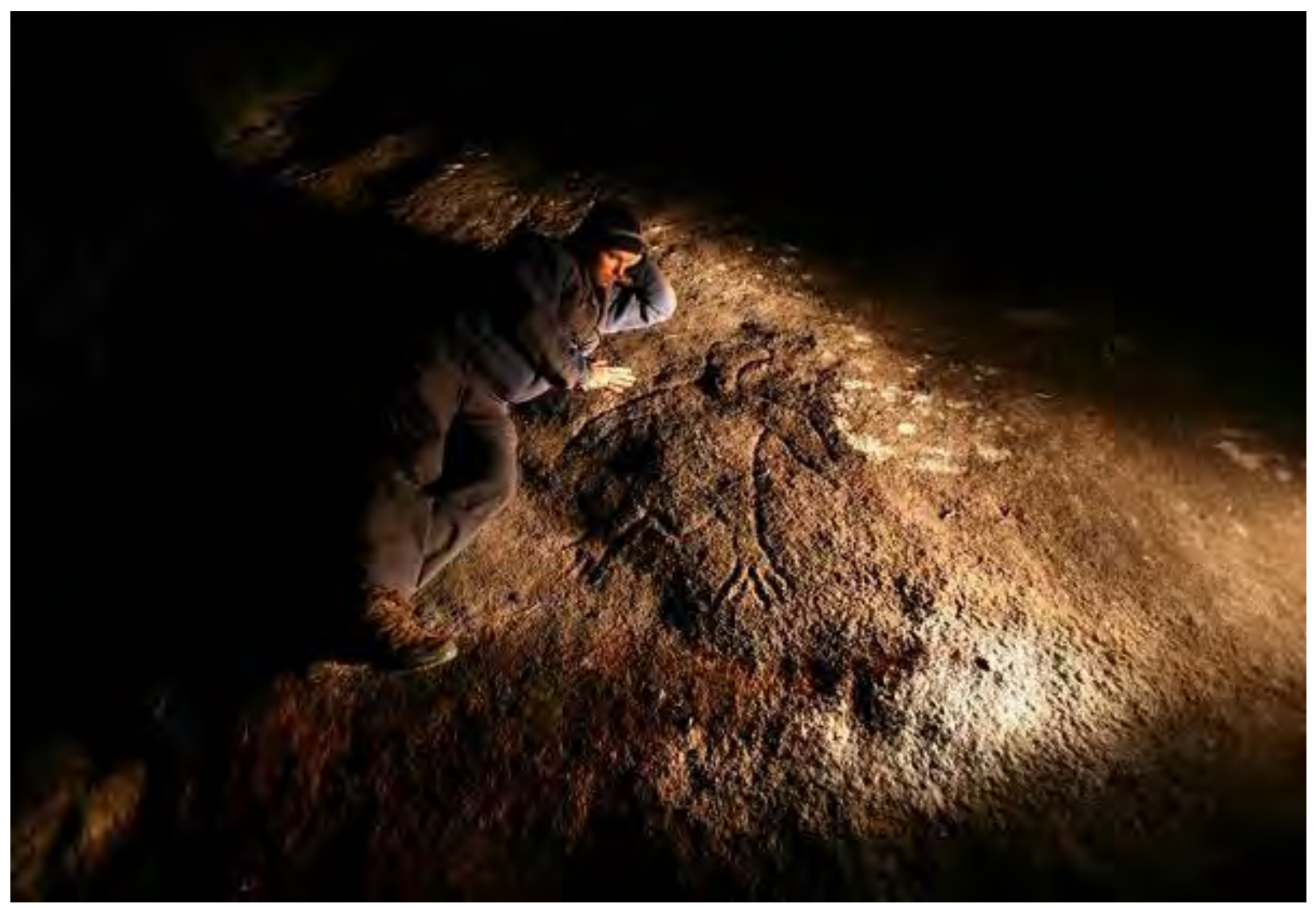

Figure 45. Matthew Kelleher next to the life-size eagle engraving (photo by Tristram Miller). 


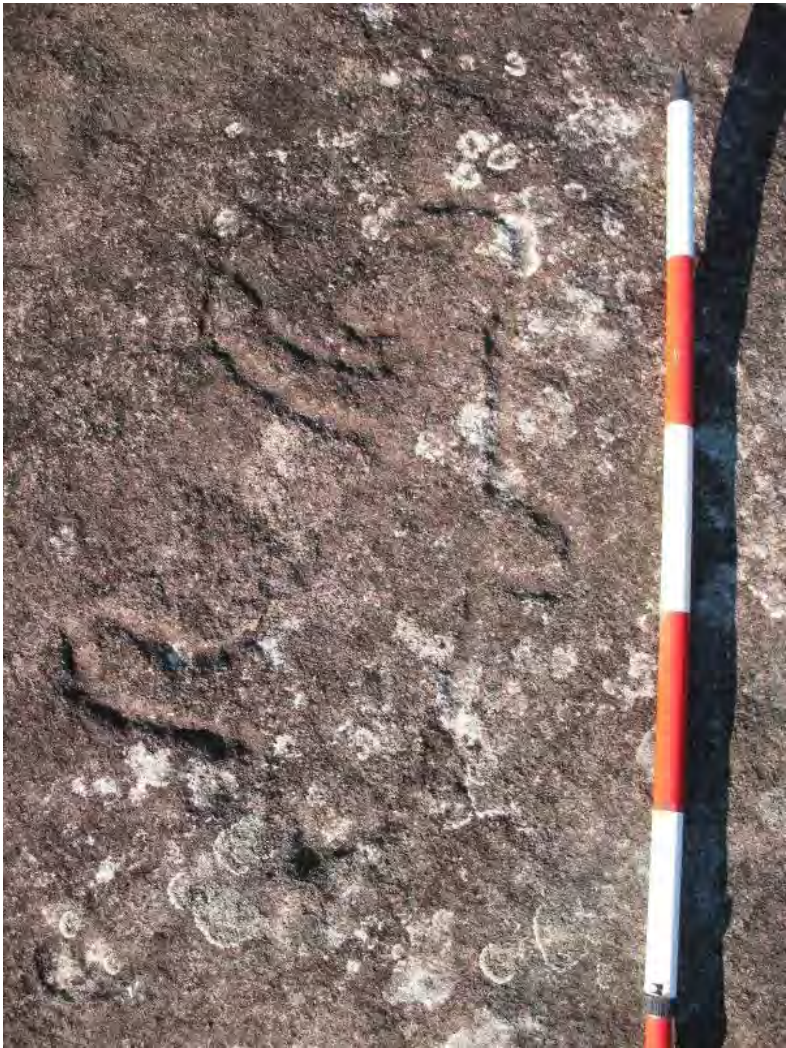

Figure 46. A profile figure with a hump on its back and emu 'bum' interpreted as an emu woman (photo by Paul S.C. Taçon).

and an evil being known as Club Foot Man (possibly a form of Daramulan and similar to an engraving in Ku-ring-gai Chase National Park, on the northern coast of Sydney) - the most important Culture Heroes for Darkinjung, Darug, Wiradjeri and other groups. As some eel depictions are associated with or are considered manifestations of the Rainbow Serpent (e.g. see McCarthy 1947, 1959) this Being may also be represented according to some elders who visited Gallery Rock.

In one composition a male figure reaches up with one arm to grab a circle while a crescent shape lies near his feet to the other side. This is similar to an engraving at Bulgandry, Kariong, on the central coast (Campbell 1899; Norris 2008), that some have interpreted as showing Biaime in relation to the sun and the moon (e.g. Norris 2008:19).

The eagle is particularly interesting because it is lifesize, faithfully executed and similar to a drawn eagle at the Eagle's Reach site that appears to 'hold' stenciled human-made objects, as a boomerang stencil was placed over one wing and a hafted stone axe (hatchet) stencil over the other. When Aboriginal community members first saw the Eagle's Reach drawing-stencil composition it was interpreted as the Eagle Ancestor because of the juxtaposition of the eagle and the material culture stencils (see Taçon et al. 2008 and below). When the Gallery Rock eagle was found it was interpreted by Aboriginal community members similarly as the Eagle Ancestor, despite lacking an association with material culture. This interpretation does not come out of the blue because for traditional peoples from Melbourne to Sydney Eagle and Crow were the ancestral leaders and creation beings of the two moieties individuals were classified into within their mainly matrilineal societies (Howitt 1904; Mathew 1899; Tindale 1941). However, depictions of the Eagle ancestor had not been previously identified in the rock art of the Sydney region by other researchers. The contemporary interpretation of the eagles as the Eagle Ancestor was reinforced by closeup visits by actual eagles on a number of occasions that Eagle's Reach and Gallery Rock were visited.

The representation of the Eagle lies between the main depiction of Biaime and one that resembles other figures classed as depictions of Daramulan in profile (e.g. see Higgs and Clegg 2004; McDonald 2008a). However, usually Daramulan depictions are very large while this one is small; but a similar-looking figure that is almost 3 metres tall (1.12 $\mathrm{m}$ wide $\mathrm{x} 2.74 \mathrm{~m}$ high) was found on a nearby rock platform. A small profile figure argued to be a representation of Daramulan by Clegg and Higgs (2004:15), from Elvina Track, Ku-rin-gai Chase National Park, is very similar in size and form to the Gallery Rock depiction and closely resembles it.

There also are two large human-eagle engravings, therianthropes (animal-headed beings with human bodies) or beings in a state of transformation (Figure 47; see Taçon and Chippindale 2001 for world-wide instances of such imagery). Aboriginal community members who have visited the site conclude it is an unrestricted site as it does not have the hallmarks of a male initiation site, such as human-like (Biaime) footprints, and the fact that there are child hand stencils in nearby shelters.

The main depiction of the figure interpreted as Biaime is large at $192 \times 80 \mathrm{~cm}$. His arms are raised up toward a macropod, his legs are spread apart, his penis appears to be circumcised and exceptionally long, much longer than any other human-like male images at the site. This may emphasise his creative power while a line across the waist suggests he wears a hair belt, a sign of initiation and a key feature for identifying Biaime for McDonald (2008a). Mathews (1893) was the first to argue that very large human male figures were portrayals of Biaime 'or the great spirit' (1893:355) while McCarthy (1946, 1954) classified all large human-like depictions as Culture Heroes. Thus, the large size and combination of engraved features supports the interpretation of this figure as Biaime for both Aboriginal community members and archaeologists. 


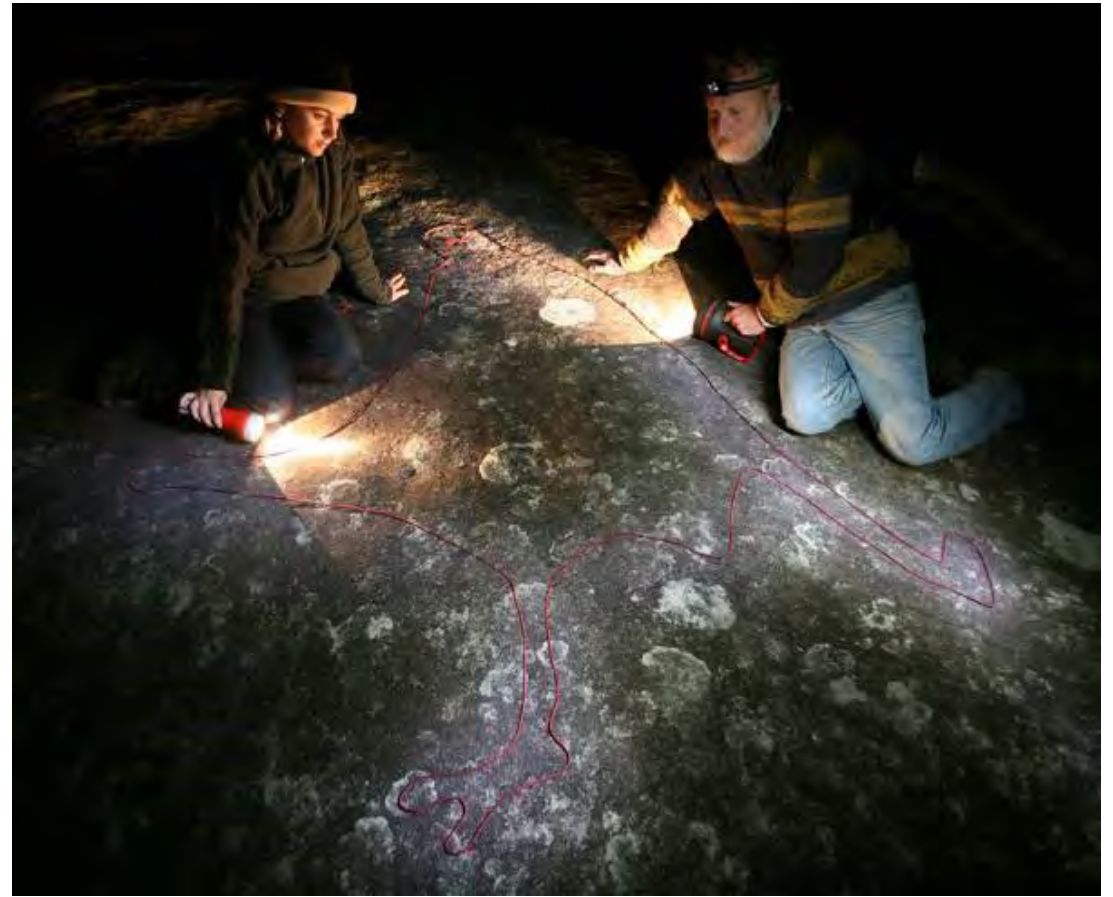

Figure 47. Sally K. May and Paul S.C. Taçon examine one of two transforming eaglehuman figures recorded at night (photo by Tristram Miller).

originally drawn in charcoal. Then it had white artefact stencils, of a boomerang and a hafted stone axe, placed over the wings as with a few sites in the Sydney region where stenciled objects were placed over body parts (McDonald pers. comm. 2010). It later was re-outlined in white, with bright white eyes added. The result is a powerful and unusual image, prompting its interpretation as a Culture Hero by Aboriginal community members.

Given the many layers of imagery at Eagle's Reach, many generations of Aboriginal people visited and marked this incredible terrain with symbols of group and individual identity. In the process some imagery, such as the main eagle, changed, as would associated interpretation. For contemporary Aboriginal people

Attenbrow (2002:128-130) provides a useful summary of descriptions and beliefs for both Biaime and Daramulan, as well as other Ancestral Beings important to Aboriginal people of the greater Sydney region. She notes 'The relationship between Baiame and Daramulan and the status of each was not the same in all parts of south-east Australia' (2002:128). In accounts of some groups there are different names for the same being; for the Wiradjuri Daramulan was Baiame's son; for other groups he was Baiame's half-brother or some other close relative. Among many groups Daramulan was portrayed with one leg, as at Gallery Rock and two other Wollemi sites close by.

\section{Links to other sites}

Eagle's Reach, the most archaeologically and Indigenously significant pigment rock art site yet found in Wollemi (Taçon et al. 2008, 2012), also lies in a remote and rugged part of Wollemi National Park and close to Gallery Rock, less than 2 kilometres away but separated by a deep gorge. It was discovered in October 1995, when four hikers chanced upon it. Our team undertook the first scientific assessment and documentation of the site in May 2003, with 206 individual images recorded, consisting of 166 drawings, 39 stencils and one painting, arranged in twelve superimposed layers (Taçon et al. 2008). One of the special features of the site is the large range of Wollemi animals drawn with great skill and accuracy. Another is the many rare motifs, such as therianthropes and an eagle depicted as if holding artefacts, as noted above. This latter image is unusual. It is the main eagle depiction at the site, the shelter is considered a teaching site associated with the Eagle Ancestor, long used by many different groups, including Darug, Darkinjung and Wiradjeri. In other words, it is seen as having been a shared space. Gallery Rock is interpreted in the same way, the Culture Hero imagery reinforcing shared identity and assisting with group cohesion.

Eagle's Reach and Gallery Rock are located near the boundary or junction of the traditional territory of the Wiradjeri, Darug and Darkinjung. The intermediate location of the sites, extensive and varied rock art imagery, a large occupation deposit at Eagle's Reach and shelters near Gallery Rock, suggests the two sites were important stops when journeying across the Wollemi area. They may have been meeting places with many spiritual associations given the large number of depictions of Culture Heroes and therianthropes. Each time a group visited stories could be told and images added, resulting in the history of these places becoming richer. Unfortunately, we will never know the full details of the use of either site or the stories that must have been told about them, although future excavation could reveal some clues. However, because Eagle's Reach has hand stencils of all sizes, including those of children, the site is not typical of those restricted only to men, to women or knowledgeable elders as identified by Kelleher (2003). Importantly, some other shelter sites close to Gallery Rock also have child hand stencils.

Field survey has revealed that both Eagle's Reach and Gallery Rock are not isolated locations or 'islands' but rather are an integral part of a network of dozens of 
sites. As the crow (and eagle) flies Gallery Rock and Eagle's Reach are $1.9 \mathrm{~km}$ apart but because of the rugged terrain there is no direct route between them. Other sites in the vicinity of both Eagle's Reach and Gallery Rock include open lithic scatters, shelters with lithics and, in some cases, wooden objects (see below), axe grinding groove clusters, open petroglyph sites and both large and small shelters with pigment art (stencils, drawings and paintings). These and other clusters of sites are linked by ridge tops and creek lines, with a few intervening rock art sites in between.

Many Wollemi sites contain components of what is at Eagle's Reach or Gallery Rock, as well as other sorts of imagery and it is not unusual for the same subjects to be expressed in dual media in the greater Sydney region (Kelleher 2003; McDonald 1991). The wombat and the eagle depictions most obviously link Gallery Rock to Eagle's Reach, both in terms of subject matter and style. These subjects are relatively rare elsewhere in the greater Blue Mountains region and parts of the Sydney region, with McDonald (2008a) noting only a few instances of wombat drawings and no eagles, and Dibden finding the same for the Upper Nepean, Sydney Basin.

Human figures at each site, although in different media, were made in the same style, and similar poses such as with upraised arms. There are therianthropes, especially in the form of human-bird creatures, depicted at each site, large macropods and diverse subject matter including over a dozen different species at each site (Taçon et al. 2008, 2010), more than at any other known rock art sites of the Greater Blue Mountains World Heritage Area.

Gallery Rock also has geometric and abstract designs, including depictions of something that consists of a circle on the end of a stick. A few kilometres northwest we recorded another large shelter site, with 50 charcoal drawings, that has drawn versions of this object. It also has numerous drawn human-like figures and a large eel done in the same style as Gallery Rock engravings, suggesting some of the same or closely related individuals made imagery in both locations. Eagle's Reach lies between Gallery Rock and the charcoal drawing site and it too has subjects in a similar manner of depiction. In other words, the engravings at Gallery Rock art part of a rock art style that includes pigment art.

Several sites were found close to Gallery Rock, including shelters with sources of white pipe clay, drawings and stone artefacts. When Gallery Rock was found in 2006 another significant discovery was a rock shelter a few kilometers away with an in situ complete hafted stone axe (Kelleher 2009:92).The stone hatchet head has two long wooden handle shafts and binding resin. Although borers have degraded part of the wooden handle shaft it is the first time a hafted axe has been found in situ anywhere in the Greater Blue Mountains World Heritage Area and in the greater Sydney region. Almost all hafted southeast Australian stone axes in museum collections were obtained through trade, as gifts or as commissioned objects from Aboriginal people in the 1800 s or early 1900 s (e.g. see Attenbrow 2002). The find compliments a wooden fire-stick located by our team in another shelter in 2003 (Taçon et al. 2005), as well as 3 blocks of resin, partial remains of two fire drills, a fire board and a small burnt bullroarer at sites on Clews Ridge, a major ridgeline to the south of Gallery Rock. Furthermore, at a site just south of Tambo Crown, several kilometres west of Gallery Rock, a wooden digging stick with a white hand stencil was found by our team.

Because wooden objects deteriorate quickly in rock shelters and are susceptible to fierce bush fires the greater Sydney region is known for they are probably less than a couple hundred years of age (but they have not been radiocarbon dated). Some rock art at Wollemi region sites that has a very recent/fresh appearance, engravings that may have been made with metal tools (see below), the occasional scarred tree and wooden objects in shelters suggest Aboriginal people were using the area well after the arrival of Europeans in New South Wales, at a time when Sydney was experiencing early rapid growth 65 kilometres away. Some contact imagery, such as drawings of horses from two widely separated Wollemi sites (e.g. see Saidin et al. 2008:41; Taçon et al. 2012), reinforces this view. One of the activities people may have been engaging in when they visited this part of Wollemi was ceremony, along with associated trade, meeting and sharing between various groups. Stories would have been told and new designs added to art sites.

\section{Contemporary and past cultural significance}

Gallery Rock is part of the Sydney region petroglyph style with a relatively common range of subject matter, such as large macropods, Biaime-like male figures, Daramulan-like profile males, female humanlike figures, dingoes and birds (see McDonald 2008a; Taçon et al. 2006). But as a focal point within a large Wollemi cultural landscape Gallery Rock is highly significant for local Aboriginal groups today as a special heritage place. Greater Blue Mountains Aboriginal communities today regard Gallery Rock and Eagle's Reach to be part of an 'Eagle Ancestor' landscape, a place of high spiritual significance for men, women and children of several language groups. Although this is a contemporary interpretation, for these Aboriginal people the sites are considered meeting and teaching places, where story-telling, song, dance and ritual ceremony would occur. Gallery Rock is also considered a meeting place for Culture Heroes by contemporary Aboriginal community members of the region and as 


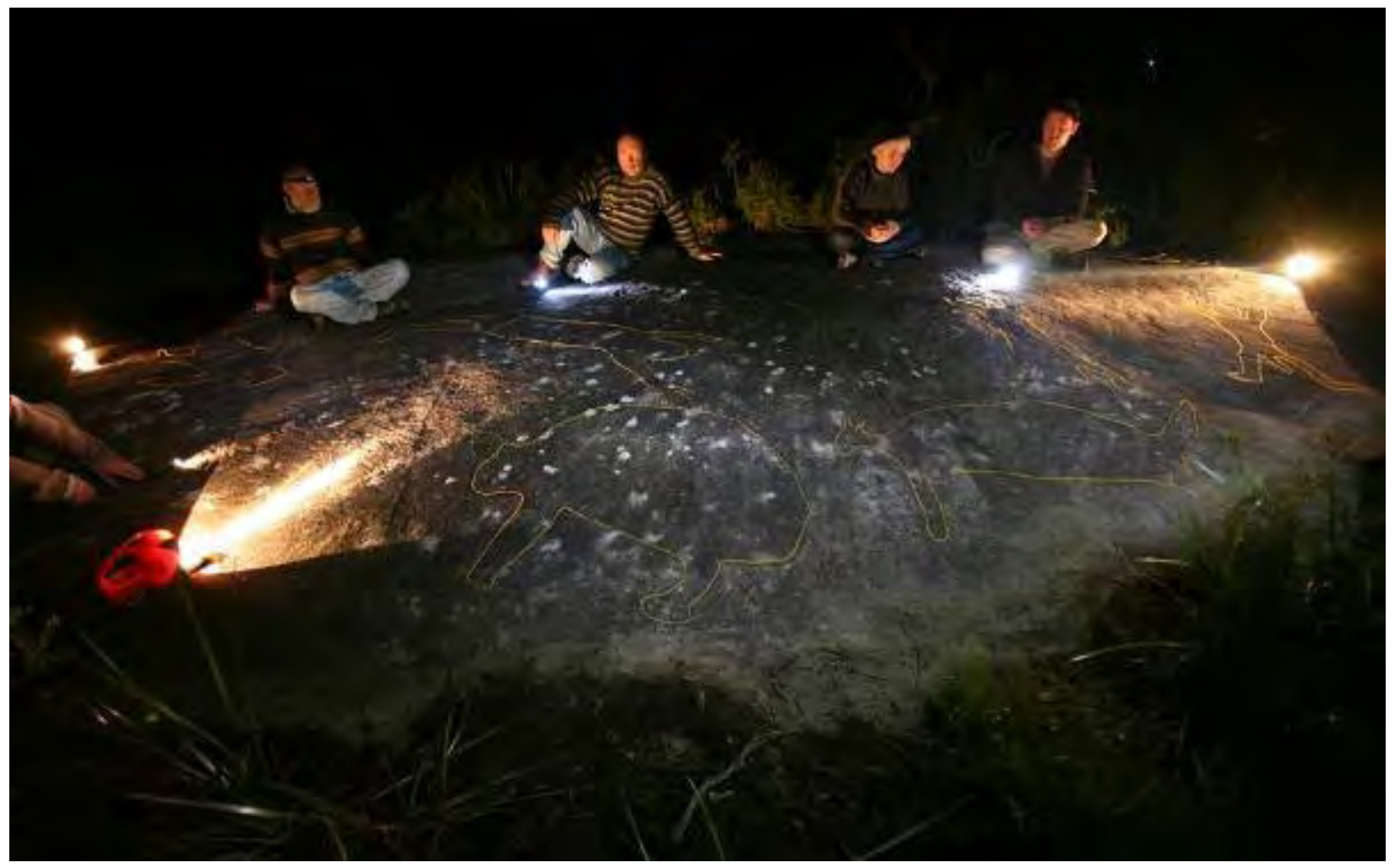

Figure 48. Examining Panel $\mathrm{C}$ at night with torches. Note the Eagle at the top left and Baiame reaching toward the wombat, middle. In the past Aboriginal ceremonies may also have been held by torch and firelight as the engravings can easily be seen this way (photo by Tristram Miller).

such is argued to be as significant as Mt. Yengo, where Biaime is said to have stepped off the Earth into the sky, an ethno-historically documented story (see Enright 1898; McDonald 1993), although opinion varies as to the accuracy of the recording in the contemporary Aboriginal community.

A reliable water source consisting of a spring and hanging swamp-fed deep pool at the northeast corner of the platform, a large shelter for camping below and the protected nature of the saddle would have made Gallery Rock an attractive stopping point for any Aboriginal group traversing this part of the Greater Blue Mountains. Surveys from Gallery Rock have shown it lies on a key access route for this part of Wollemi, with travel possible in several directions. A few engravings, deeper and much fresher in appearance have a different morphology to the rest and appear relatively recent. A couple engraving may have been made with metal tools as they have sharp, straight angular edges rather than smooth somewhat rounded edges, suggesting postEuropean contact visits to the site. The site also has many features of places for and of ceremony, including reliable water, room for lots of people, several entrance ways, unusual landscape location and so forth (Kelleher 2003). Parts of these ceremonies may have taken place at night, the engravings illuminated with fire and torchlight (Figure 48). Barry and Clegg (2005) and Clegg (2009:69) discuss this sort of activity in relation to fire scars at engraving sites they label as 'snames'. However, we found no evidence of snames at Gallery Rock.

\section{Contact period imagery}

During our research only a few sites with definite contact imagery, such as horses, a pig, a musket and other introduced subjects, were documented in the Wollemi area (Taçon et al. 2012). Clegg and Ghantous (2003) and McDonald (2008b) have reviewed the limited number of rock art images produced after contact in greater Sydney. Clegg and Ghantous (2003:263) suggest 'representations of European objects were incorporated into Aboriginal ritual and rock-art' but McDonald (2008b:16) concludes 'The rock art evidence would suggest that the arrival of the outsiders resulted in the termination of the Sydney region's symbolical and artistic culture. There is no evidence that rock art production continued with changed function (either in place of production or in graphic vocabulary)'.

Attenbrow (2002), on the other hand, suggests the practice of rock art production continued on the fringes of greater Sydney well after contact with Europeans:

Exactly when the last engravings, drawings, paintings or stencils were made in the Sydney region cannot be said with certainty. In adjacent regions to the north between the Hawksbury River 
and Hunter Valley, such as the Macdonald River valley, where the full impact of British settlement came later, such activities continued until at least the 1850s. Darginung people from north-west of the Hawksbury River as well as non-Aboriginal informants told RH Mathews of places where figures had been painted and engraved (including an engraved figure of a man dressed in a shirt, trousers and a hat and carrying an axe) as late as 1855 (2002:151; the location of the engraved man is in Cattai Creek; see also various listed under note 128 on page 202).

In agreement with Attenbrow's suggestion, Dibden (2011) argued from an archaeological point of view for a context of contact for much of the rock art in the southern Sydney Basin. She contends the Sydney Catchment lands acted as a bush refuge and were places that people marked to try to mediate colonial encounters. This is supported by Huntley et al. (2011) who noted that the carbon signatures found consistently in the hand stencils of the southern Sydney Basin were only centuries old and thought to be from saliva. Perhaps Wollemi was a similar refuge.

Mathews (1897a:98) said of the carved man that it is evidently intended to represent a white man going into the bush to cut timber, carrying his axe over his shoulder'. He notes 'the shape of the axe shows that it belongs to the same period, before American axes were introduced' and that the figure was likely carved with an 'iron tomahawk' (1897a:98). Thus rock art activity at Darkinjung (Darginung sites), not far to the east of Gallery Rock and Eagle's Reach, continued until the mid-1800s.

\section{Changing worldviews and/or religious renewal}

Swain (1993), following on from Durkheim (1915:330), argues that Aboriginal people of the Sydney area incorporated key aspects of European religious belief into their worldviews as a result of contact in the Sydney region, and the great changes such contact brought about. He contends that the 'all-father' creator being was invented or 'transmuted' from Eaglehawk, one of two key Ancestral Birds (the other being Crow) that headed moieties people of the region belonged to (Swain 1993:147; see also van Toorn 2006:39).Swain argues this new Being was known by several names including Biaime and Daramulan:

What has rarely been seriously entertained is the possibility that south-east Australian conceptions of existence could have been adapted so as to accommodate the devastating effects upon social and territorial organization. My thesis is that not only were Aboriginal worldviews restructured but that Aboriginal people responded with remarkable speed to the seemingly insurmountable challenge before them. I contend that the major changes had already occurred by the 1830s, when initial reports on Aboriginal societies were being prepared. Indeed, even at a prima facie level, it is virtually impossible to conceive how Aboriginal traditions in this region could have survived had it been otherwise (Swain 1993:117).

Recently, van Toorn (2006), Clegg (2009) and Lewis (2009) have reinvigorated this hypothesis, using Sydney region rock art both to support it and as a means of interpretation. However, Attenbrow (2002: 129) suggests there is good evidence to support the idea that belief in Biaime and Daramulan predates the arrival of Europeans (see also Eliade 1973, Howitt 1904 [1996]). Engraving sites have not been directly dated in the Sydney region and McDonald (2008b) argues little rock art activity occurred after Europeans arrived. All of this supports the contention that at least some, if not most, depictions of Biaime and Daramulan pre-date contact. In other words, the concept of these Culture Heroes was not 'invented' after contact with Europeans.

Thus Aboriginal people would not be incorporating a new male Christian 'God' into their cosmologies in the way Swain, van Toorn, Clegg and Lewis suggest but rather would have adapted an existing conception in a way that would also make sense of the new. A renewed interest in particular Aboriginal Culture Heroes could also have come about because of their similarities to Christian figures, leading to new forms of ceremonial practice and perhaps new interpretations of some rock art imagery. Attempts to harness the power of Culture Heroes at rock art sites in order to combat or come to grips with change may also have been undertaken for, as McNiven and Russell (2002:37) note: 'By extending a counter-reading of sketchy historical sources to include archaeological evidence such as contact rock art, we have revealed the existence of a post-contact Indigenous landscape that was regulated by ceremonial strategies and systems of place marking designed to combat European colonisation'.

Furthermore, the reconnection with powerful imagery, such as the figures found at Gallery Rock, would have been ideally suited as a strategy for reaffirming traditional relationships to cultural places and belief, in a time when both were being rapidly encroached on. This is a more likely possibility than Aboriginal people totally transforming their worldviews. Aboriginal people were not merely observers of change but actively participated in and against it because Indigenous cosmology was strong and adaptable. And because rock art is fixed in place within cultural landscapes it is can regularly be reinterpreted and re-socialised as part of the contemporary cultural space, as indeed the Aboriginal community has 
done through The Landscape of Blue Mountain Rock Art research project. That aspects of rock art meaning are emphasized in new ways is not surprising given the deaths, loss of land and cataclysmic change Aboriginal people experienced but this does not mean that old beliefs were simply abandoned and replaced with new, introduced powerful Beings. Indeed, places like Gallery Rock would have been important for reaffirming identity in the face of change. And if, as we assume, most of Gallery Rock's engravings, including those of Baiame, were made prior to the arrival of Europeans then an Aboriginal conception of an all-father creator most likely already existed when the British stepped ashore in what was to be Sydney, as Howitt (1904), Parker (1905), Mathews (1904) and others suggest.

\section{Conclusions}

Research since 2001 has shown that what we call Wollemi National Park is not a place of true wilderness but rather a place that has been traversed, inhabited and marked for thousands of years. Within it, Gallery Rock is an unusual site in terms of its imagery in that it contains a large number of different Culture Heroes. Indeed, there is no comparable site anywhere in Australia that contains all the key Culture Heroes/ Ancestral Beings of a particular region. Usually, depictions of different Beings are dispersed between sites instead of all being depicted in any one place. Gallery Rock lies on a key access route for east-west travel across the southern part of Wollemi. Among other things, the engraved imagery of Culture Heroes would have demonstrated and reaffirmed group cohesion as McDonald (2008a:286) has argued for some Sydney Basin sites with Culture Hero depictions. It could also be an aggregation site, defined for hunter-gatherers by Conkey (1980) as "places in which affiliated groups and individuals come together' (McDonald 1993:87). That there is a reliable source of drinking water at the edge of the platform, a large shelter for camping, lots of open space for ceremony and other seasonal activities in what is otherwise a dense forest environment supports the idea that it was an aggregation site. Besides traditional reasons for aggregation and ceremony, such as initiations, the most recent ceremonies, like those in lower-lying areas nearby documented by Matthews (1897b, 1898), may have functioned to address changes happening to Aboriginal societies of the greater region as a result of contact with Europeans.

Today, both Gallery Rock and Eagle's Reach are considered by local Aboriginal people to reflect many aspects of south-eastern Australian Aboriginal identity and tradition - places connected to the Eagle Ancestor with depictions about ceremony, totemic relationships, other Culture Heroes, oral history, local ecology, social relationships and individual experience (Taçon et al.
2008, 2010). They are key locations within a cultural landscape spread across a wild, rugged part of the Greater Blue Mountains World Heritage Area. With the arrival of Europeans in greater Sydney, the area where Gallery Rock and Eagle's Reach are located may also have been one of the last refuges of the region, a place of great cultural significance not yet impacted by new arrivals and cultural change. At sites like Gallery Rock and Eagle's Reach Aboriginal people of the area could engage in tradition in new ways, in response to change and unobserved by encroaching outsiders.

\section{Acknowledgements}

Research was supported by ARC Discovery grant DP0877463, Hardie Holdings Pty Ltd, National Geographic Society Research and Exploration Grant 7658-04, the Australian Museum, Griffith University, the Blue Mountains World Heritage Institute and the University of New South Wales. We thank the Aboriginal communities of the Greater Blue Mountains World Heritage Area, the then Department of Environment and Climate Change within the government of New South Wales and the many people of varied backgrounds who participated in our field work. James Woodford is thanked for his special interest in and promotion of our research. Gallery Rock recording was assisted by Bentley Dean, Michael Jackson, Sally K. May, Tristram Miller, Alison Nightingale, Chel Roxburg and Roger Uluru Shannon. John Clegg is thanked for inspiration and on-site advice at Gallery Rock.

\section{References}

Attenbrow, V. 2002. Sydney's Aboriginal past. Investigating the archaeological and historical records. Sydney: UNSW Press.

Barry, M. and J. Clegg 2005. Snames and Science, in J.K.K. Huang and E.V. Culley (eds) Making marks: graduate studies in rock art research at the new millennium: 65-80. American Rock Art Research Association Occasional Paper No. 5.

Brady, L. and P.S.C. Taçon 2016. Relating to rock art in the contemporary world: navigating symbolism, meaning and significance. Boulder: University Press of Colorado.

Campbell, W.D. 1899. Aboriginal carvings of Port Jackson and Broken Bay. (Memoirs of the Geological Society of NSW Ethnological Series 1). Sydney: Department of Mines and Agriculture,

Clegg, J. 2009. Support for a new sky Hero from a conquered land, in P. Bahn (ed.) An enquiring mind: studies in honour of Alexander Marshack: 57-83. Oxford: Oxbow Books.

Clegg, J. and S. Ghantous 2003. Rock-paintings of exotic animals in the Sydney Basin, New South Wales, Australia. Before Farming 2003/1 (7):257-66. 
Conkey, M. 1980. The identification of hunter-gatherer aggregation sites - the case of Altamira. Current Anthropology 21(5):609-630.

Dibden, J. 2011. Drawing in the land: rock-art in the Upper Nepean, Sydney Basin, New South Wales. Unpublished PhD thesis. Canberra: Australian National University.

Durkheim, E. 1915. The elementary forms of religious life. New York: The Free Press.

Eliade, M. 1973. Australian religions: an introduction. Ithaca: Cornell University Press.

Enright, W.J. 1898. Aboriginal carvings in the Wollombi district, NSW. Science of Man 1:181-183.

Higgs, S. 2003. Emu bums and second generation knobs.; a taxonomic look at some Sydney region rock engravings. BA (Hons) thesis. Sydney: The University of Sydney.

Higgs, S. and J. Clegg. 2004. Sydney Daramulan engravings. Unpublished paper presented at the 10th International Rock Art Congres, Agra, India.

Howitt, A.W. 1904 [1996]. The native tribes of South-East Australia. London: MacMillan and Co Limited.

Huntley,J., A. Watchman and J.Dibden 2011.Characteristics of a pigment art sequence: Woronora Plateau, New South Wales. Rock Art Research 28(1):85-98.

Kelleher, M. 2003. Archaeology of sacred space: the spatial nature of religious behavior in the Blue Mountains National Park Australia. PhD thesis. Sydney: University of Sydney.

Kelleher, M. 2009. Aboriginal art in the Blue Mountains, in E. Stockton and J. Merriman (eds) Blue Mountains Dreaming: the Aboriginal heritage (second edition): 73104. Lawson:

Blue Mountains Education and Research Trust.

Layton, R. 1992. Australian rock art: a new synthesis. Cambridge: Cambridge University Press.

Lewis, B. 2009. Rock-art, landscape and transformative vistas of Devil's Rock Maroota: new interpretative perspectives for a Sydney region rock-art site, in G. Nash and D. Gheorghiu (eds), The archaeology of people and territoriality: 55-75. Budapest: Archaeolingua Alapítvány.

Mathew, J. 1899. Eaglehawk and Crow. A study of the Australian Aborigines and an inquiry into their origin and a survey of Australian languages. London: Рипол Классик.

Mathews, R.H. 1893. Rock paintings by the Aborigines in caves on Bulgar Creek, near Singleton. Journal of the Royal Society of New South Wales 27:353-358.

Mathews, R.H. 1897a. Rock carving by the Australian Aborigines. Proceedings of the Royal Society of Queensland 12:96-98.

Mathews, R.H. 1897b. The Burbung of the Darkinung tribe. Proceedings of the Royal Society of Victoria 10:1-12.

Mathews, R.H. 1898. Initiation ceremonies of Australian tribes. Proceedings of the American Philosophical Society 38:54-73.
Mathews, R.H. 1904. Ethnological notes on the Aboriginal tribes of NSW and Victoria. Journal and Proceedings of the Royal Society of NSW 38:203-381.

McCarthy, F.D. 1946. Records of rock engravings in the Sydney district XXXIII-XXXVII. Mankind 3(9):266-272.

McCarthy, F.D. 1947. Records of rock engravings in the Sydney district: 38. Mankind 3(11):322-329.

McCarthy, F. D. 1954. Records of rock engravings of the Sydney district, Nos. 41-55. Mankind 5(1):8-32.

McCarthy, F.D. 1959. Rock engravings of the SydneyHawkesbury District Pt 2: some important ritual groups in the County of Cumberland. Records of the Australian Museum 24:203-216.

McDonald, J. 1991. Archaeology and art in the Sydney region: context and theory in the analysis of a dualmedium art style, in P. Bahn and A. Rosenfeld (eds) Rock art and prehistory: papers presented to Symposium $G$ of the AURA Congress, Darwin 1988: 78-85. Oxbow Monograph 10. Oxford: Oxbow Books.

McDonald, J. 1993. On a clear day you can see Mt. Yengo: or, Investigating the archaeological manifestations of culturally significant foci in the prehistoric landscape, in J. Steinbring, A. Watchman, P. Faulstich and P. Taçon (eds) Time and space: dating and spatial consideration in rock art research: 1-18. Melbourne: Occasional AURA Publication No. 8. Archaeological Publications.

McDonald, J. 2008a. Dreamtime superhighway: Sydney Basin rock art and prehistoric information exchange. (Terra Australis 27). Canberra: ANU E Press.

McDonald, J. 2008b. Rock art and cross-cultural interaction in Sydney: how did both sides perceive the other, in P.M. Veth, P. Sutton and M. Neale (eds) Strangers on the shore: early coastal contacts with Australia: 46-89. Canberra: National Museum of Australia Press.

Officer, K.L.C. 1992. The edge of the sandstone: style boundaries and islands in south-eastern new South Wales, in J. McDonald and I.P. Haskovec (eds) State of the art: regional rock art studies in Australia and Melanesia: 6-14. Melbourne: Occasional AURA Publication No. 6. Archaeological Publications.

Parker, K. 1905. The Euahlayi Tribe: A Study of Aboriginal Life in Australia. London: Archibald Constable and Co.

Norris, R. 2008. Emu Dreaming. Australasian Science 29(4):16-19.

Ross, J., Westaway, K., Travers, M., Morwood, M.J. and Hayward, J., 2016. Into the past: a step towards a robust Kimberley rock art chronology. PloS one, 11(8), p.e0161726.

Saidin, M., P.S.C. Taçon, D. Yang, G. Nash, S.K. May and B. Lewis 2008. Illustrating the past: the rock art of Southeast Asia. Current World Archaeology 29:40-48.

Sim, I.M. 1966. Records of the rock engravings of the MacDonald River District, N.S.W. (Occasional Papers in Aboriginal Studies 7). Canberra: Australian Institute of Aboriginal Studies. 
Sim, I.M. 1969. A gallery of cave art in the Macdonald River District, NSW. Archaeology and Physical Anthropology in Oceania 4(2):144-79.

Stanbury, P. and J. Clegg 1990. A field guide to Aboriginal rock engravings. Oxford: Oxford University Press.

Swain, T. 1993. A place for strangers: towards a history of Australian Aboriginal being. Cambridge University Press, Cambridge.

Taçon, P.S.C. and C. Chippindale 1998. An archaeology of rock-art through informed methods and formal methods, in C. Chippindale and P.S.C. Taçon (eds) The archaeology of rock-art: 1-10. Cambridge: Cambridge University Press.

Taçon, P.S.C. and C. Chippindale 2001. Transformation and depictions of the First People: animal-headed beings of Arnhem Land, N.T., Australia, in K. Helskog (ed.) Theoretical perspectives in rock art research: 175210. Oslo: Novus Forlag.

Taçon, P.S.C., W. Brennan, S. Hooper, M. Kelleher and D. Pross 2005. Greater Wollemi: a new Australian rockart area bordering Sydney. International Organisation of Rock Art (INORA) Newsletter 43:1-6.

Taçon, P.S.C., M. Kelleher, W. Brennan, S. Hooper, and D. Pross 2006. Wollemi petroglyphs, NSW, Australia: an unusual assemblage with rare motifs. Rock Art Research 227-238.

Taçon, P.S.C., M. Kelleher, G. King and W. Brennan 2008. Eagle's Reach: a focal point for past and present social identity within the northern Blue Mountains World heritage area, New South Wales, Australia, in I. Sanz, D. Fiore, and S.K. May (eds) Archaeologies of art: time, place and identity: 195-214. Walnut Creek: Left Coast Press.

Taçon, P.S.C., W. Brennan, M. Kelleher and D. Pross 2012. Differential Australian cave and rockshelter use during the Pleistocene and Holocene, in H. Moyes (ed.) Sacred Darkness: a global perspective on the ritual use of caves: 135148. Boulder: University Press of Colorado.

Taçon, P.S.C., R.S. Chapple, J. Merson, D. Ramp, W. Brennan, G. King and A. Tasire 2010. Aboriginal rock art depictions of fauna: What can they tell us about the natural history of the Greater Blue Mountains World Heritage area? In D. Lunney, P. Hutchings and D. Hochuli (eds) The Natural history of Sydney: 58-73. Sydney: Royal Zoological Society of New South Wales. Taçon, P.S.C., A. Paterson, J. Ross and S.K. May 2012. Picturing change and changing pictures: contact period rock art of Australia, in J. McDonald and P. Veth (eds) A companion to rock art: 420-436. Chichester: Blackwell Publishing Ltd.

Tindale, N.B. 1941. Eagle and crow myths of the Maraura tribe, Lower Darling River, New South Wales. Records of the South Australian Museum 6(3).

Van Toorn, P. 2006. Writing never arrives naked: early Aboriginal cultures of writing in Australia. Canberra: Aboriginal Studies Press. 